Research Article

\title{
A community based comparative cross- sectional study to assess the effects of mobile phone on quality of sleep in smart phone users and non- users in Central India
}

\author{
Bhavishya Rathore $^{1 *}$, Nisha Singh ${ }^{1}$, Yogendra Chouhan ${ }^{2}$, Indu Rathore ${ }^{3}$, Soumitra Sethia ${ }^{1}$
}

\author{
${ }^{1}$ Department of Community Medicine, Gandhi Medical College, Bhopal, Madhya Pradesh, India \\ ${ }^{2}$ Shreya Diagnostic Center, Harda, Madhya Pradesh, India \\ ${ }^{3}$ Pathology Department, RKDF Medical College, Bhopal, Madhya Pradesh, India
}

Received: 03 June 2016

Accepted: 01 July 2016

\author{
*Correspondence: \\ Dr. Bhavishya Rathore, \\ E-mail: rathorebhavishya25@gmail.com
}

Copyright: (c) the author(s), publisher and licensee Medip Academy. This is an open-access article distributed under the terms of the Creative Commons Attribution Non-Commercial License, which permits unrestricted non-commercial use, distribution, and reproduction in any medium, provided the original work is properly cited.

\section{ABSTRACT}

Background: Mobile phones are no longer simply a communication device now-a-days, rather has become an indispensable part of human life. Mobile phones have transformed from necessity to the level of status symbol. Smart phones are a newer generation of cellular phones with integrated computer related functions capable of performing various tasks based on number of applications. The extensive use of smart phones in recent years had led to exposure of human beings to radio frequency electromagnetic field (RF-EMF) which could have adverse effects on sleep. Objectives of the study was to compare the effects of mobile phone on quality of sleep in smart phone users and nonusers using Pittsburgh Sleep Quality Index (PSQI). 2. To educate the study subjects about the hazards of excessive smart phone usage.

Methods: Study design- Prospective cross- sectional comparative study. Study subjects- 166 working class adults working in various offices in Bhopal. Inclusion criteria - Those who were using any type of mobile phones and gave consent to participate in the study. Exclusion criteria -Those who had any recent trauma or chronic illness related to sleep. Ethical consideration-Permission taken from Head of the department of Community Medicine, Gandhi Medical College, Bhopal. Verbal consent was obtained from the study participants.

Results: Out of 166 study participants 92 were male and 74 were female of which mostly belonged to the age group of 20-30 years with mean 26.75 years and SD 5.12years. 97.6\% were graduate and above. Participants showing a better subjective sleep quality amongst non-users of smart phone was significant $(\mathrm{p}=0.00185)$ and the number of participants showing no problem to keep up enough enthusiasm to get things done were more in non-users than users with difference being statistically significant ( $\mathrm{p}=0.0146)$.

Conclusions: We should restrict the use of mobiles to minimum for sound mind and good health.

Keywords: Smart phone, PSQI, Sleep quality

\section{INTRODUCTION}

Mobile phones have become an indispensible part of human life in modern era. Human beings cannot imagine life without mobile phones. In the era before mobile phones, human life was very different. ${ }^{1}$ Smart phones are a newer generation of mobile phones with integrated computer related functions capable of performing various tasks based on number of applications. ${ }^{2}$ Mobile phones are no longer simply a communication device now-adays, rather has become an indispensable part of human life and have transformed from necessity to the level of status symbol because of the countless perks that it provides. The extensive use of smart phones in recent 
years had led to exposure of humans to radio frequency electromagnetic field (RF-EMF) of $30 \mathrm{KHz}-300 \mathrm{GHz}$ both during receiving and transmitting the signals. Studies on human beings have reported the adverse effects of EMF emitted by mobile phones on sleep electroencephalograms and reduced melatonin production. ${ }^{3-5} \mathrm{~A}$ biological explanation for an association between exposure to RF-EMF and impaired sleep quality has been hypothesized which relates to the suppressed nightly melatonin secretion by electromagnetic field exposure. Smart phone usage is a very activating behaviour engaging our brain and fingers. ${ }^{6}$ Smart phones are capable of processing more information than other phones as they include many features like games, access to the internet and social networking, messaging, videos, multimedia, and navigation, in addition to their use for communication. Thus the usage of smart phones can have more adverse effects on sleep as compared to the nonusers of smart phones. ${ }^{7}$

'If you're typing, that's not part of a normal sleep preparation routine', said Doctor Jeffrey Bluhm with the providence sleep disorder center. 'Cell phones are so convenient that they're an inconvenience.' -Haruki Murakami. ${ }^{8}$ Hence this study was done to find out whether smart phones have more hazardous effects on sleep in comparison to the normal mobile phones.

Objectives of the study was to compare the effects of mobile phone on quality of sleep in smart phone users and non- users using Pittsburgh Sleep Quality Index (PSQI) and to educate the study subjects about the hazards of excessive smart phone usage.

\section{METHODS}

A prospective comparative cross- sectional study was carried out for a period of 4 months (September 2015 to December 2015) on 166 working class adults working in various govt. offices in ward no. 8 in Bhopal, with the help of structured questionnaire prepared using the Pittsburgh Sleep Quality Index (PSQI).

Initially permission was sought from the Head of the department of Community Medicine, Gandhi Medical College, Bhopal to carry out this study. A list of all the govt. offices such as banks etc., present in ward no. 8 (which is also the field practice area of Department of Community Medicine, Gandhi Medical College, Bhopal),was prepared out of which 10 govt. offices were randomly chosen by lottery method. The staff members working in these 10 offices comprised our study population. Pilot testing was performed in the department of community medicine to identify common response categories based on which the structured questionnaire was modified and standardized. Permission was also sought from the authorities incharge in these offices after explaining the objectives of our study and the benefits that it could bring to their offices in the form of a healthy work force.
The staff members those who were using any type of mobile phones and gave consent to participate in the study were included after taking verbal informed consent and assuring full confidentiality, while those who had any recent trauma or chronic illness related to sleep chronic insomnia for which the person is on regular medication and were absent on the day of interview were excluded from the study which led to a total of 166 study participants.

Questionnaire was given to the participants to be filled by them recalling their past months' experiences regarding sleep followed by a short educational intervention in which a power point presentation highlighting the harmful effects of mobile phones on sleep were shown to the subjects and one time counselling was done.

Data was entered in MS Excel 2007 and analysed using Epi-info7.1. Results were expressed in terms of proportions and percentages. Unpaired T-test was used to compare the means between the two groups and $\mathrm{P}$ value < 0.05 was taken to be statistically significant.

\section{RESULTS}

The results of the study have been assessed on the basis of seven components of pittsburgh sleep quality index (PSQI). Table 1 show the distribution of study participants according to various demographic characteristics. Out of total 166 participants, 92 $(55.42 \%)$ were males and $74(44.58 \%)$ were females. Maximum study participants $(90.36 \%)$ belonged to the age group 20-30 years. Majority of them were Hindu by religion $(79.51 \%)$ and almost all $(97.6 \%)$ were highly educated with graduation and above.

Table 1: Demographic characteristics of the study sample.

\begin{tabular}{|ll|}
\hline Demographic characteristics & No. $(\mathbf{n = 1 6 6 ) ( \% )}$ \\
\hline Sex & $92(55.42)$ \\
\hline Male & $74(44.58)$ \\
\hline Female & \\
\hline Age group (years) & $150(90.36)$ \\
\hline $20-30$ & $12(7.22)$ \\
\hline $31-40$ & $4(2.4)$ \\
\hline$>40$ & $26.75 y r s, 5.12 y r s$ \\
\hline Mean age, sd & \\
\hline Religion & $132(79.51)$ \\
\hline Hindu & $26(15.66)$ \\
\hline Muslim & $2(1.20)$ \\
\hline Sikh & $6(3.61)$ \\
\hline Christian & \\
\hline Education & $4(2.4)$ \\
\hline Higher secondary & $162(97.6)$ \\
\hline Graduation and above & \\
\hline
\end{tabular}


Table 2: Sleep patterns in smart phone users and non- users based on PSQI.

\begin{tabular}{|c|c|c|c|}
\hline Variables & $\begin{array}{l}\text { Smart } \\
\text { phone } \\
\text { users }(n=83)\end{array}$ & $\begin{array}{l}\text { Non-smart } \\
\text { phone } \\
\text { users }(\mathbf{n}=\mathbf{8 3})\end{array}$ & $\begin{array}{l}\mathbf{P} \\
\text { value }\end{array}$ \\
\hline $\begin{array}{l}\text { Mean habitual } \\
\text { sleep efficiency }\end{array}$ & $80.06 \%$ & $91.04 \%$ & $>0.05$ \\
\hline $\begin{array}{l}\text { Average time } \\
\text { for which } \\
\text { mobile is being } \\
\text { used } \\
\text { In a day }\end{array}$ & & & \multirow[t]{5}{*}{$>0.05$} \\
\hline$<1 \mathrm{hr}$ & 3 & 18 & \\
\hline $1-2 \mathrm{hr}$ & 30 & 40 & \\
\hline $2-4 \mathrm{hr}$ & 40 & 21 & \\
\hline$>4 \mathrm{hr}$ & 8 & 5 & \\
\hline $\begin{array}{l}\text { Hours of sleep } \\
\text { during the day }\end{array}$ & & & \multirow[t]{5}{*}{$>0.05$} \\
\hline$<1 \mathrm{hr}$ & 29 & 43 & \\
\hline $1-2 \mathrm{hr}$ & 31 & 26 & \\
\hline $2-4 \mathrm{hr}$ & 12 & 7 & \\
\hline$>4 \mathrm{hr}$ & 11 & 7 & \\
\hline $\begin{array}{l}\text { Time taken to } \\
\text { fall asleep }\end{array}$ & & & \multirow[t]{5}{*}{$>0.05$} \\
\hline$<15 \min$ & 32 & 48 & \\
\hline $16-30 \mathrm{~min}$ & 33 & 27 & \\
\hline $31-60 \mathrm{~min}$ & 14 & 6 & \\
\hline$>60 \mathrm{~min}$ & 4 & 2 & \\
\hline $\begin{array}{l}\text { Whether taken } \\
\text { medicine to fall } \\
\text { asleep }\end{array}$ & & & \multirow[t]{5}{*}{$>0.05$} \\
\hline $\begin{array}{l}\text { Not during last } \\
\text { month }\end{array}$ & 63 & 72 & \\
\hline$<1$ in a week & 12 & 8 & \\
\hline $\begin{array}{l}1-2 \text { times in a } \\
\text { week }\end{array}$ & 7 & 3 & \\
\hline $\begin{array}{l}>2 \text { times in a } \\
\text { week }\end{array}$ & 1 & 0 & \\
\hline $\begin{array}{l}\text { Trouble } \\
\text { staying awake } \\
\text { while driving, } \\
\text { eating meals, } \\
\text { or engaging in } \\
\text { social activity }\end{array}$ & & & \multirow[t]{5}{*}{$>0.05$} \\
\hline $\begin{array}{l}\text { Not during last } \\
\text { month }\end{array}$ & 57 & 63 & \\
\hline$<1$ in a week & 20 & 17 & \\
\hline $\begin{array}{l}1-2 \text { times in a } \\
\text { week }\end{array}$ & 4 & 2 & \\
\hline $\begin{array}{l}>2 \text { times in a } \\
\text { week }\end{array}$ & 2 & 1 & \\
\hline
\end{tabular}

Table 2 shows the comparison of sleep patterns found in smart phone users and non- users. Overall quality of sleep was found to be good in non-smart phone users though these were not statistically significant.
Out of 166 study participants $92(55.42 \%)$ were males and $74(44.58 \%)$ were females of which majority belonged to $20-30$ years age group $(90.36 \%)$, with mean age 26.75 years and standard deviation of 5.12 years. Majority of the participants were Hindu (79.51\%), $15.66 \%$ were Muslims. $97.6 \%$ were highly educated with graduation and above and rest $2.4 \%$ were educated up to higher secondary.

Mean habitual sleep efficiency of smart phone users and non- users was found to be $80.06 \%$ t $91.04 \%$ respectively. Difference was noted in average number of hours of usage of the mobile phones, time taken to fall asleep, number of participants taking medicine to fall asleep and trouble staying awake while driving, eating meals, or engaging in social activities among the two groups of study subjects but these were found to be statistically insignificant.

However, difference in subjective sleep quality as reported by the two groups was found to be statistically significant ( $\mathrm{p}=0.001857)$, as shown in Figure 1. Also the difference reported among the two groups to keep up enough enthusiasm to get things done was found to be statistically significant $(\mathrm{p}=0.0146)$, as shown in Figure 2.

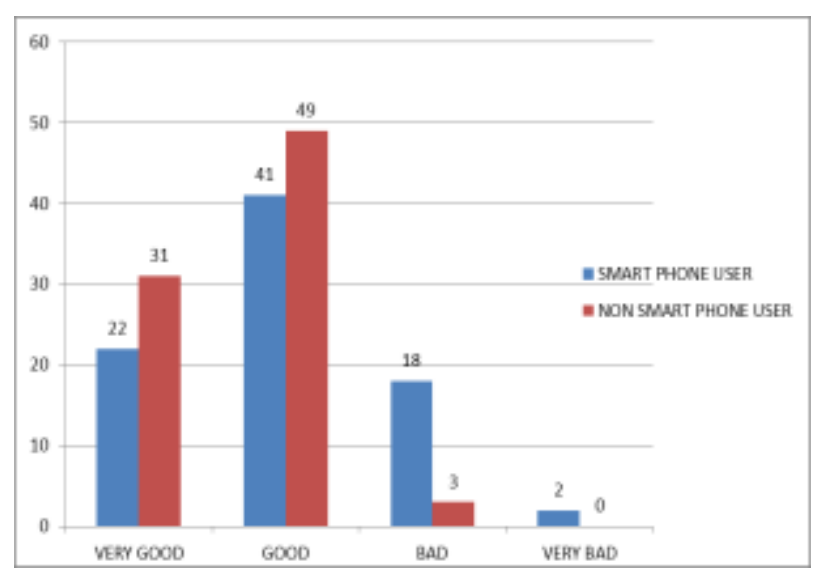

Figure 1: Subjective sleep quality in the study subjects.

In Figure 1, the $\mathrm{P}$ value is 0.001857 and the result is statistically significant (since $P$ value $<0.05$ ) which implies a strong association between subjective sleep quality and smart phone usage. Those who did not used smart phones, were relatively more satisfied with their quality of sleep and vice versa.

Figure 2 shows the level of problem it has been for the participants to keep up enough enthusiasm to get various things done. The $\mathrm{P}$ value was found to be $0.0146(<0.05)$ and thus the test results are statistically significant which implies that smart phone users subjectively felt the lack of enthusiasm to get things done. 


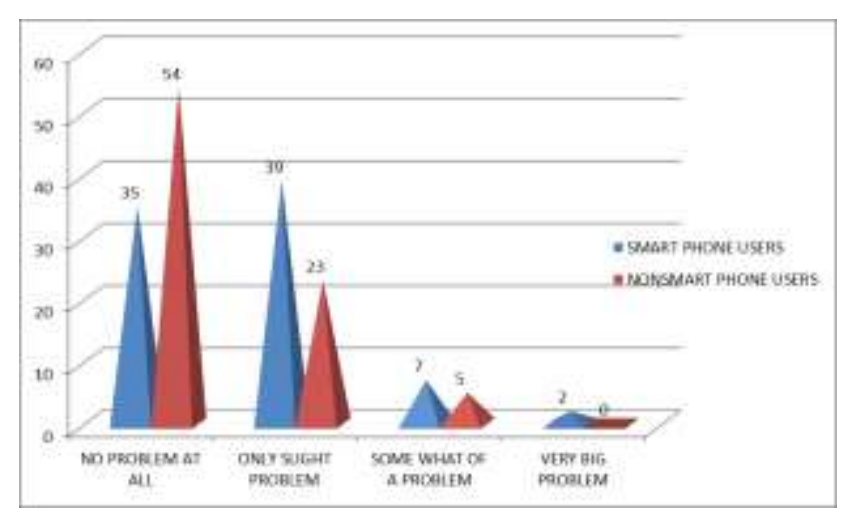

Figure 2: shows how much of a problem it has been for the participants to keep up enough enthusiasm to get things done.

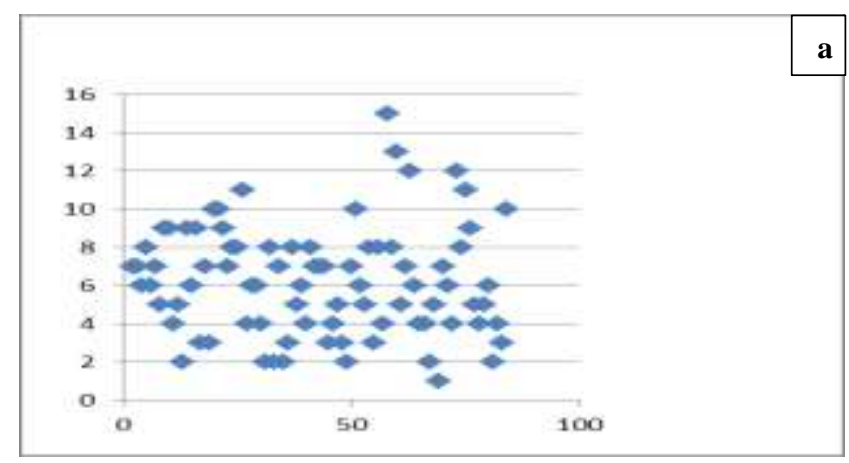

(a) Smart phone users- Score: 6.22

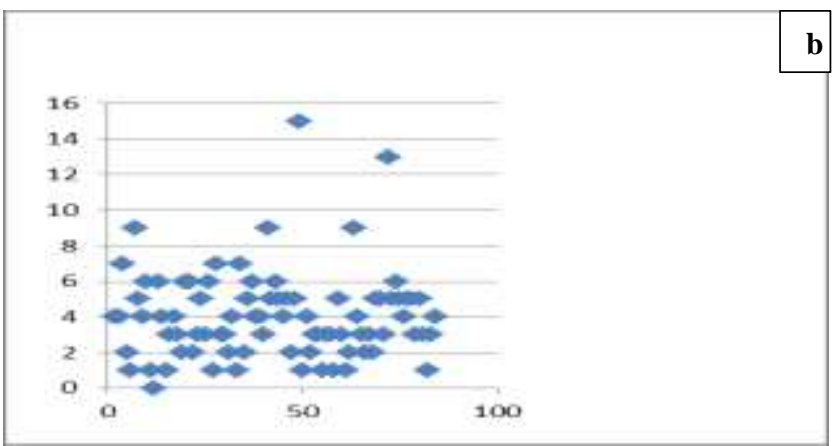

(b) Nonsmart phone users- Score: 4.03

Figure 3(a and b): Scatter diagram showing global PSQI score in smart phone users and non-users.

The single-tailed $P$ value is less than 0.0001 , the difference is considered to be extremely statistically significant.

Mean global PSQI score which shows quality of sleep was 6.22 in smart phone users and 4.03 in non-users which signifies an improved sleep quality and this is also statistically significant ( $\mathrm{p}$ value $<0.0001$ ).

\section{DISCUSSION}

Now days, there is not much information about the relationship between use of smart phone before sleep and its effect on sleep quality. Observations of the present study are based on a small group of study participants of Bhopal, M.P. (India), which may not necessarily reflect the problem of all over the world. The main findings of our study are as follows: subjective sleep quality and enthusiasm to get things done (component of PSQI scale) were significantly higher in non-users of smart phone. The use of smart phones has increased rapidly in recent years. This may result in Smartphone addiction, which represents the convergence of existing mobile phone and Internet addiction problems into smartphone addiction (Hwanget al). Overuse of a Smartphone may cause various physical and psychological health problems. Some studies have evaluated the relationship between smart phones and sleep disturbances. ${ }^{9}$ Canan et al found an association between Internet addiction and impaired sleep.

Hutter et al investigated the influence of cell phones on health and sleep quality in Australia. They conducted a descriptive cross sectional study on 365 individuals for one year and demonstrated a significant relationship between using cell phones and somatic complaints, especially headache. However, unlike us they could not find a significant relationship between using cell phones and sleep quality. ${ }^{8}$

Lemo et al evaluated adolescents' electronic media usage at night, along with sleep disturbances and depressive symptoms. Park found a negative association between the level of physical activity and risk of problematic Internet use via the mediation of sleep satisfaction and stress in adolescents.

An et al found the associations between problematic Internet use and adolescents' physical and psychological symptoms showed that excessive Internet use had indirect negative effects through sleep deprivation.

Our results showed that daytime dysfunction, which is a component of sleep quality, was higher in smart phone users. This result may be due to sleep deregulation. There were positive correlations between subjective sleep quality, sleep disturbance, and daytime dysfunction, in our study. It has been reported that problematic Internet use may affect sleep construction, such as by reducing rapid eye movement (REM) sleep, slow-wave sleep, and sleep efficiency or that the bright light of a computer screen may suppress melatonin secretion and delay the onset of sleep..$^{10,11}$

Moreover, Loughran et al reported the adverse effect of electromagnetic fields emitted by mobile phones on sleep electroencephalograms. Similarly, Huber et al reported that electromagnetic field exposure (mobile phone usage) in the evening influences physiological factors such as sleep quality and the melatonin rhythm, probably by influencing the brain activity - particularly that of the pineal gland; it may also result in altered cerebral blood flow and brain electrical activity. 
Young adults tend to be unaware of just how much time they really spent on Smartphone, and the effect this might have on their academic performance and social interaction (Meena, Mittal and Solanki). Because sleep is a significant biological mechanism related to mood regulation (Thomée et al) students whose sleep is disrupted because of technology use may be more likely to experience markers of depression such as loss of energy, concentration problems, and daytime sleepiness (Adams and Kisler, 2013;NSF,2011).

When used moderately, a smartphone may contribute to improving emotional and psychological well-being. In addition, smartphone communications can be used to relieve stressful situations (Park and Lee). Moreover, we think that smartphone overuse may lead to depression and/or anxiety, which in turn leads to sleep problems. Several limitations of the present study should be considered. The relatively small study population was one such issue as the study participants did not represent the total population. All subjects were well-educated adults. Longitudinal studies and samples with different educational and age backgrounds are needed. The crosssectional design, which is not the best way to evaluate causal relations, also limited the results. Furthermore, all of the scales were self-rated by the participants and are subjected to recall bias. Finally, the literature in this field is not yet rich enough. In conclusion, our study expanded the literature to include smart phone overuse and sleep quality in medical students. Although the effects of behavioural addictions, including smart phone addiction, on our lives are rising, little research has been carried out on these issues. Thus, our study provides an important contribution to find out the effects on sleep quality with smart phone overuse.

\section{CONCLUSION}

After conducting this study, we found that the quality of sleep was much better in non-smart phone users suggesting that limiting the use of mobile phones can improve sleep quality. The quality of sleep was assessed by pittsburgh sleep quality index (PSQI) scores. Ideally, PSQI score should be less than 5. A difference of 2.19 in mean PSQI score was seen among the two groups which is suggestive of a better sleep quality in non-users of smart phones. The mean habitual sleep efficiency in nonsmart phone users was higher by $8.08 \%$ than in smart phone users. This study recommends that the amount of smart phone use should be limited to a minimum for a good quality sleep.

\section{ACKNOWLEDGEMENTS}

The authors are thankful to Dr. D.K.Pal, Professor and Head, Department of Community Medicine, Gandhi Medical College, Bhopal for granting permission to carry out this study and to all the study participants and office authorities for their co-operation during the study.

\section{Funding: No funding sources \\ Conflict of interest: None declared \\ Ethical approval: The study was approved by the Institutional Ethics Committee}

\section{REFERENCES}

1. Bhise AT, Ghatule AA, Ghatule AP. Study of mobile addiction among student's w.r.t. gender and education.

2. Ballagas R, Borchers J, Rohs M, Sheridan JG. The smart phone: a ubiquitous input device. Pervasive Computing. 2006;5:70-7.

3. Michael M, Colin B, Mika K. The health hazards of mobile phones. Br Med J. 2000;320:1288-9.

4. Burch JB, Reif JS, Noonan CW, Ichinose T, Bachand AM, Koleber TL, et al. Melatonin metabolite excretion among cellular telephone users. Intern J Radiation Biol. 2002:78.

5. Jarupat S, Kawabata A, Tokura H, Borkiewicz A. Effects of the $1900 \mathrm{MHz}$ electromagnetic field emitted from cellular phone on nocturnal melatonin secretion. J Physiol Anthropol. 2003;22:61-3.

6. Buysse, DJ, Reynolds CF, Monk TH, Berman SR, Kupfer DJ. (PSQI):Psychiat Res. 1989; 28:193-213.

7. Demirci K, Akgönül M, Akpinar A. Relationship of smartphone use severity with sleep quality, depression, and anxiety in university students. J Behav Addict. 2015;4(2):85-92.

8. Sanjay D, Harish S, Bhagwat AK, Arpita B, Abhilasha G, Alia KZ, and Akansha S. A study to evaluate mobile phone dependence among students of a medical college and associated hospital of central India. Ind J Comm Med. 2010:35.

9. Hutter HP, Moshammer H, Wallner P, Kundi M. Subjective symptoms, sleeping problems and cognitive performance in subjects living near mobile phone base stations. Occup Environ Med. 2006;63(5):307-13.

10. Lemola S, Perkinson-Gloor N, Brand S, DewaldKaufmann JF, Grob A. Adolescents' electronic media use at night, sleep disturbance, and depressive symptoms in the smartphone age. J Youth Adolesc. 2015;44(2):405-18.

11. Higuchi S, Motohashi Y, Liu Y, Ahara M, Kaneko Y. Effects of VDT tasks with a bright display at night on melatonin, core temperature, heart rate, and sleepiness. J Appl Physiol. 2003;94(5):1773-6.

Cite this article as: Rathore B, Singh N, Chouhan Y, Rathore I, Sethia S. A community based comparative cross- sectional study to assess the effects of mobile phone on quality of sleep in smart phone users and non- users in Central India. Int J Community Med Public Health 2016;3:2078-82. 